\title{
Anxiety during magnetic resonance imaging of the spine in relation to scanner design and size
}

B. M. Ahlander, Jan Engvall and E. Ericsson

The self-archived postprint version of this journal article is available at Linköping University Institutional Repository (DiVA):

http://urn.kb.se/resolve?urn=urn:nbn:se:liu:diva-173275

N.B.: When citing this work, cite the original publication.

Ahlander, B. M., Engvall, J., Ericsson, E., (2020), Anxiety during magnetic resonance imaging of the spine in relation to scanner design and size, Radiography, 26(2), 110-116.

https://doi.org/10.1016/j.radi.2019.09.003

Original publication available at:

https://doi.org/10.1016/j.radi.2019.09.003

Copyright: Elsevier

http://www.elsevier.com/

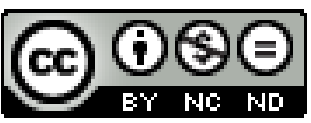




\section{Anxiety during Magnetic Resonance Imaging of the spine in relation to scanner design and size}

Britt-Marie Ahlander 1 , Jan Engvall 2,3, Elisabeth Ericsson 4

${ }_{1}$ Ryhov County Hospital, SE-551 85 Jönköping, Sweden.

${ }_{2}$ Department of Clinical Physiology, Linköping University, SE-581 83 Linköping, Sweden. Jan.Engvall@regionostergotland.se

${ }_{3}$ Center of Medical Image Science and Visualization, Linköping University, SE-581 83

Linköping, Sweden.

${ }_{4}$ Faculty of Medicine and Health, School of Health Science, Örebro University, SE-701 82 Örebro, Sweden.

elisabeth.ericsson@oru.se

Corresponding author address: $\quad$ britt-marie.ahlander@oru.se

Tel.: (+46) 707652189

Faculty of Medicine and Health,

School of Health Science

Örebro University

SE-701 82 Örebro

Sweden

${ }_{1}$ Present address: Faculty of Medicine and Health, School of Health Science, Örebro University, SE-701 82 Örebro, Sweden.

Declarations of interest: none

The authors gratefully thank the staff in the MRI-units at the participating hospitals for valuable assistance. 


\begin{abstract}
Introduction: Magnetic resonance imaging in closed-bore scanners sometimes provokes anxiety but closed-bore designs have gradually become wider and shorter. Open scanners may be easier to tolerate.
\end{abstract}

Aim: To compare patient anxiety during MRI between scanners with bore diameters of 60 $\mathrm{cm}$ and $70 \mathrm{~cm}$, and to determine the current level of patient anxiety and experience in open scanners in a clinical setting.

Method: Consecutive patients referred for examination of the spine in $60 \mathrm{~cm}$ and $70 \mathrm{~cm}$ and one open scanners participated. Scheduling for examination in the open scanner was primarily to address patient problems with closed bores. Four established/validated questionnaires, answered before, directly after and one week after the MRI-examination were used, measuring anxiety, fear and depression.

Result: 155 patients responded to the questionnaires before and immediately after the examination. 109 responded one week later. No difference was found in the patient scores of anxiety between the $60 \mathrm{~cm}$ and the $70 \mathrm{~cm}$ scanners on the examination day. At follow-up, patients in the $60 \mathrm{~cm}$ bore rated their examination experience lower $(\mathrm{p}<0.05)$, compared to patients in the $70 \mathrm{~cm}$ bore. Patients in the open scanner rated higher levels of anxiety $(p<0.001)$ before, directly after and one week after the examination, compared to closed bore scanners.

Conclusion: Scanners with a $70 \mathrm{~cm}$ diameter seem more tolerable than those with a $60 \mathrm{~cm}$ bore. Patients referred to the open scanner were more likely to express anxiety than those in the closed bore, possibly due to selection bias. Still, patient anxiety in MRI is challenging and further research required.

Keywords: Magnetic Resonance Imaging, MRI examinations, anxiety, patient care. 


\section{Introduction}

Magnetic resonance imaging (MRI) is a versatile diagnostic tool which may be used to evaluate all body parts in a wide range of conditions. It is used worldwide in high numbers and the use is continuously increasing ${ }^{1}$. In the United States, 118 MRI-examinations per1000 inhabitants are performed annually and in Germany $136 / 1000^{2}$. Sweden is a late adopter with 42 MRI examinations per 1000 inhabitant in $2013^{3}$.

If the patient has no contraindication, MRI is known to be safe and can be repeated whenever needed ${ }^{4,5}$. However, an investigation in the MRI tunnel is known to be an anxietyridden procedure for some patients. The loud noise and the long duration of the examination negatively affect patients. The enclosed environment of the tunnel is known to induce anxiety ${ }^{6-10}$, which may affect $1-30 \%$ of patients $9,11,12$. Anxiety may result in premature termination of an MRI study as well as the patient refusing follow-up ${ }^{13}$. Anxiety causes unwanted motion artefact, which may preclude a correct diagnosis ${ }^{14}$. Worldwide, 2 million scans are aborted each year due to claustrophobia ${ }^{15}$.

Different interventions have been suggested to reduce anxiety, such as offering psychological support or relaxation training, performing the study with the patient lying prone ${ }^{16-19}$ or prescribing pharmacological sedation ${ }^{5}$.

Technological advances allowing a shorter and wider bore may make future examinations less trying. Scanners with 1.5 Tesla (T) field strength dominate the market and often have a $60 \mathrm{~cm}$ bore. Newer scanners frequently have bores with a diameter of $70 \mathrm{~cm}$. To the best of our knowledge, no one has compared patient experience examined in scanners with diameters of $60 \mathrm{~cm}$ and $70 \mathrm{~cm}$.

A completely open design is possible but the field strength, recently up to $1.0 \mathrm{~T}$, will be lower than in closed-bores, and the lower signal will negatively affect image quality. Studies 
have compared anxiousness of patient suffering from increased risk of claustrophobic experience in open vs closed bore scanners, were patients in open bores have had significantly decreased anxiety ${ }^{13,15}$. There is a lack of studies evaluating if open configured MR systems increase patient comfort and reduce anxiety to an acceptable level in a clinical setting. Thus, it is important to determine the patient experience for possible future improvements.

Therefore, the primary aim of this study was to compare patient anxiety during MRI between scanners with bore diameters of $60 \mathrm{~cm}$ and $70 \mathrm{~cm}$. The secondary aim was to illustrate the current level of patient anxiety and the total patient experience in an open scanners in a clinical setting.

\section{Methods}

\section{Scanners}

The study was performed at three different MRI sites, using three different scanning systems: Siemens "Avanto 1.5T" with $60 \mathrm{~cm}$ tunnel (Siemens Healthcare, Erlangen Germany), the wider tunnel was “GE 1.5 T 450” (GE Healthcare, Milwaukee, Wisconsin, USA) with a $70 \mathrm{~cm}$ bore diameter and the open scanner was "Panorama $1.0 \mathrm{~T}$ " (Philips Healthcare, Best, the Netherlands),

\section{Patients}

Consecutive patients referred for MRI of the spine were asked to participate. During examinations the patients were placed on a spine coil with no surface coil over the patient. All patients had an alarm and they were in constant verbal contact with the radiographer during the examination. The investigations were performed between August 2015 and May 2017. The open scanner received a dominant proportion of referrals where patients had asked specifically to be examined in an open design. Inclusion criteria were: referral for MRI of the 
spine to diagnose possible disc hernia; age 18 years or older; ability to speak and write the Swedish language, and lack of contraindications for MRI. An invitation to participate in the study was included in the scheduling letter for the examination.

\section{Measures}

Four different qustionnaires, used in earlier studies were patient anxiety in connection with MRI has been evaluated ${ }^{20,21}$ were used to characterize the patients. Spielberger State and Trait anxiety - state (STAI-S), STAI-S, measures state (situational), 20 items ${ }^{22}$. Hospital Anxiety and Depression scale (HAD) is developed in two parts, one measuring anxiety and one depression, seven items each ${ }^{23}$. The Magnetic Resonance Imaging-Fear survey schedule (MRI-FSS), consists of nine statements from the Fear Survey Schedule ${ }^{24}$ defined by Lukins et al. ${ }^{25}$. The Magnetic Resonance Imaging- Anxiety Questionnaire (MRI-AQ) is divided in two factors; "anxiety" (12 items) and "relaxation" (three items) ${ }^{20}$. All questionnaires are well known. STAI, HAD and MRI-AQ have previously been validated. $20,22,23$

Single items: Patient "experience" and "worry" during the examination were graded on a ten-point scale by patients and staff independently. The items have been used in previous MRI-study ${ }^{21}$. All staff members had extensive experience in performing MRI and were trained by the lead author how to use the assessment scale before the start of the study. Patients who chose to participate responded to questionnaire before (HAD, MRI-FSS, STAIS), immediately after (MRI-AQ, MRI-FSS, Single items "worry" and experience") and one week after the examination (MRI-AQ, HAD, MRI-FSS, Single items). The staff ranked their perception of patient experience and worry throughout the examination on a ten-point scale. Each questionnaire took about ten minutes to answer. 


\section{Ethical considerations}

The study was approved by the Regional Ethical Review Board. It followed the Declaration of Helsinki ${ }^{26}$ and the principles of Good Clinical Practice ${ }^{27}$. Written informed consent was obtained from all participants after a full explanation of the study procedure. The patients were informed that study participation was voluntary and that they could withdraw from participation whenever they wished without negative consequences.

\section{Data analyses}

The calculation of sample size was based on the prevalence of anxiety in patients undergoing MRI examinations in previous research using STAI. Based on an expected effect size of $40 \%$, an alpha set at 0.05 and a power of 0.80 , a sample size of 50 participants in each study arm was sufficient for the study.

Descriptive statistics was used to present participants characteristics. Parametric data was expressed as mean \pm standard deviation (SD) and Student's t-test was used for test of significance.

When data on an ordinal scale level had a skewed, non-Gaussian distribution according to the Kolmogorov-Smirnov test, median and quartiles were used. For comparison of data collected directly after the examination and one week later, the Wilcoxon signed rank test was used. The Mann-Whitney U-test was used for comparisons between study groups and a Chi Square test was used for comparison between those who answered the questionnaire once or twice. A two-tailed $p$-value of $\leq 0.05$ was regarded as statistically significant. Data was analyzed using SPSS version 25 (IBM, New York, USA). 


\section{Result}

\section{Participants}

174 patients referred for examination in the 60 or $70 \mathrm{~cm}$ scanners were asked to participate.

106 accepted and answered the questionnaires before and after the examination, resulting in a response rate of $61 \% .81$ of the 106 also answered the questionnaires a second time, one week after the examination. For the open scanner 62 patients were asked to participate, 49 accepted, response rate 79\%. 28 answered a second time, one week later (fig 1).
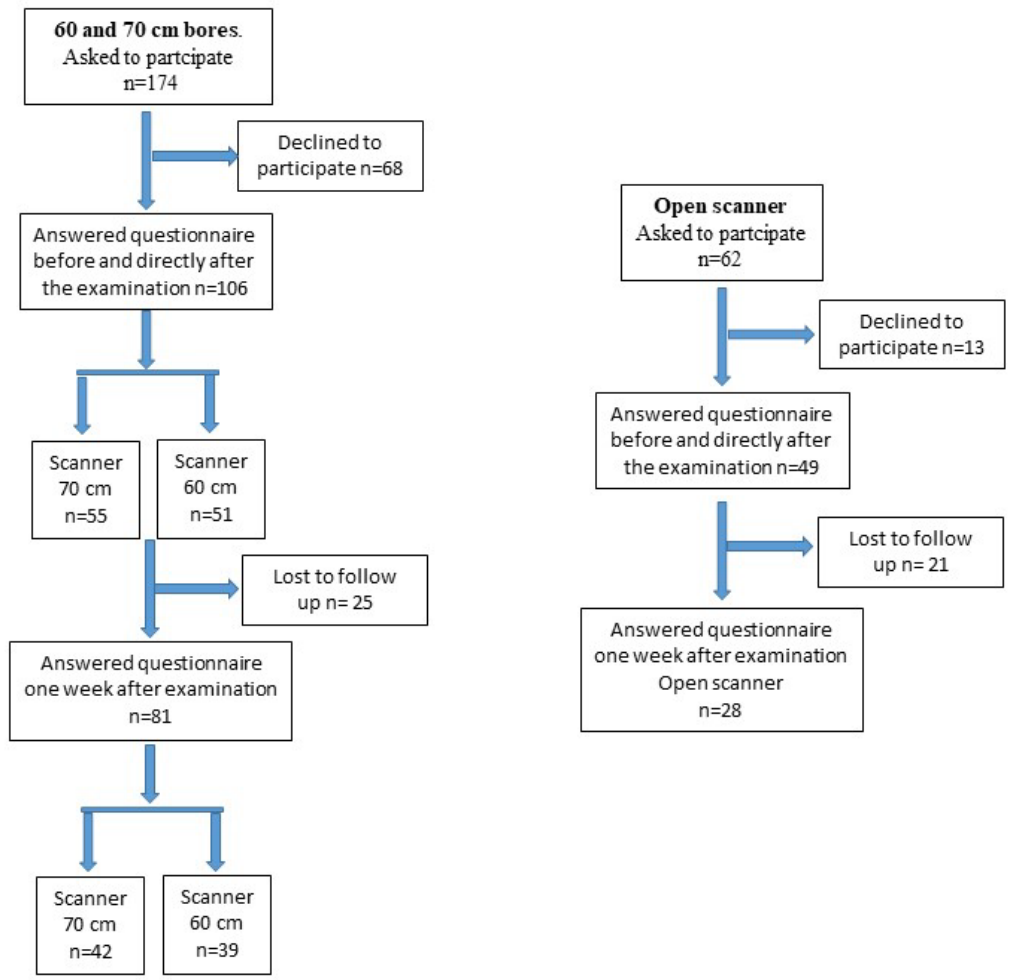

Figure 1, Flow diagram

Age and gender did not differ between those who participated $(55.5 \pm 12.0$ years, female $n=81$ and male $n=74)$ and those who did not $(52.4 \pm 13.0$ years, female $n=51$ and male $n=30)$.

Significantly higher level of anxiety was found in the group who answered the questionnaires once (HAD-A $p=0.005$, for MRI-FSS $p=0.006$, for MRI-AQ $p=0.013$ ) compared to those who also answered the questionnaire one week later. 
There was no significant difference regarding age between the three groups. As for gender, a significantly higher proportion of females were referred to the open scanner compared to the $60 \mathrm{~cm}$ and $70 \mathrm{~cm}$ scanners $(\mathrm{p}=0.001)$ (Table 1$).$

Table 1. Distribution of sample size, gender, age and scanners

\begin{tabular}{|c|c|c|c|c|c|}
\hline Variables & & $\begin{array}{l}70 \mathrm{~cm} \\
(\mathrm{n}=55)\end{array}$ & $\begin{array}{l}60 \mathrm{~cm} \\
(\mathrm{n}=51)\end{array}$ & $\begin{array}{l}\text { Open } \\
(\mathrm{n}=49)\end{array}$ & Total \\
\hline Agreed to participate, $n$ & & 55 & 51 & 49 & 155 \\
\hline Gender male/female, $n$ & & $37 / 18$ & $24 / 27$ & $14 / 35$ & $75 / 80$ \\
\hline \multicolumn{6}{|l|}{$\begin{array}{l}\text { Age in years } \\
\text { mean } \pm \text { SD (min-max) }\end{array}$} \\
\hline & All & $\begin{array}{c}56.4 \pm 9.8 \\
(29-72)\end{array}$ & $\begin{array}{l}54.9 \pm 14.4 \\
(18-81)\end{array}$ & $\begin{array}{l}54.9 \pm 11.6 \\
(26-77)\end{array}$ & $\begin{array}{l}55.5 \pm 12.0 \\
(18-81)\end{array}$ \\
\hline & Male & $\begin{array}{l}57.4 \pm 10.1 \\
(29-72)\end{array}$ & $\begin{array}{l}54.8 \pm 15.7 \\
(18-81)\end{array}$ & $\begin{array}{l}51.4 \pm 11.9 \\
(35-76)\end{array}$ & $\begin{array}{l}55.4 \pm 12.5 \\
(18-81)\end{array}$ \\
\hline & Female & $\begin{array}{c}54.5 \pm 8.9 \\
(37-69)\end{array}$ & $\begin{array}{c}55.0 \pm 15.7 \\
(23-78)\end{array}$ & $\begin{array}{c}56.2 \pm 11.4 \\
(26-77)\end{array}$ & $\begin{array}{c}55.4 \pm 11.5 \\
(23-78)\end{array}$ \\
\hline
\end{tabular}

$\mathrm{n}=$ number of participants

\section{Before the examination}

No difference was found regarding anxiety, measured with HAD A, MRI-FSS, STAI-S, between patients referred for examination of the spine in the $60 \mathrm{~cm}$ or the $70 \mathrm{~cm}$ bore scanners. The patients in the open scanner scored significantly higher levels of anxiety than those in the closed bores. No difference was found between the groups regarding depression (HAD-D) (Table 2).

Table 2. Result from questionnaire answered before the examination

\begin{tabular}{lcccccc}
\hline & $\begin{array}{c}70 \mathrm{~cm}^{\text {a) }} \\
(\mathrm{n}=55)\end{array}$ & $\begin{array}{c}60 \mathrm{~cm}^{\text {a }} \\
(\mathrm{n}=51)\end{array}$ & $\begin{array}{c}\mathrm{p} \text {-value } \\
70 / 60^{\mathrm{b})}\end{array}$ & $\begin{array}{c}\text { Open }{ }^{\mathrm{a})} \\
(\mathrm{n}=49)\end{array}$ & $\begin{array}{c}\mathrm{p} \text {-value } \\
70 / \text { open }^{\text {b) }}\end{array}$ & $\begin{array}{c}\mathrm{p} \text {-value } \\
60 / \text { open }^{\text {b) }}\end{array}$ \\
\hline HAD A & $5(3-7)$ & $3(1-8)$ & 0.291 & $7(5-9)$ & $\mathbf{0 . 0 0 1}$ & $\mathbf{0 . 0 0 1}$ \\
HAD D & $3(1-5)$ & $2(0-7)$ & 0.336 & $3(1-6.5)$ & 0.474 & 0.088 \\
MRI-FSS & $14(11-18)$ & $12(10-17.25)$ & 0.204 & $19(16-26.5)$ & $<\mathbf{0 . 0 0 1}$ & $<\mathbf{0 . 0 0 1}$ \\
STAI-S & $35(27-44)$ & $32(26-46)$ & 0.106 & $43(35.5-48.5)$ & $\mathbf{0 . 0 0 3}$ & $<\mathbf{0 . 0 0 1}$ \\
\hline \hline
\end{tabular}

HAD A= Hospital Anxiety and Depression scale Anxiety, Hospital Anxiety and Depression scale Depression, MRIFSS=magnetic Resonance Imaging-Fear Survey Schedule, STAI-S= Spielberg State and Trait Index-State, ${ }^{\text {a) }}$ Median (interquartile range), ${ }^{\mathrm{b}}=$ Mann Whitney U-test, $\mathrm{n}=$ number of participants 


\section{Immediately after the examination}

Immediately after the examination, no difference was found between patients examined in the $60 \mathrm{~cm}$ or $70 \mathrm{~cm}$ scanners. Patients examined in the open scanner experienced significantly higher levels of anxiety measured with all rating scales (Table 3 ).

Table 3. Result from questionnaires answered directly after the examination

\begin{tabular}{|c|c|c|c|c|c|c|}
\hline & $\begin{array}{c}70 \mathrm{~cm}^{\mathrm{a})} \\
(\mathrm{n}=55)\end{array}$ & $\begin{array}{c}60 \mathrm{~cm}^{\mathrm{a})} \\
(\mathrm{n}=51)\end{array}$ & $\begin{array}{l}\text { p-value } \\
70 / 60^{\text {b) }}\end{array}$ & $\begin{array}{c}\text { Open }^{\text {a) }} \\
(\mathrm{n}=49)\end{array}$ & $\begin{array}{c}\text { p-value } \\
\text { 70/open }{ }^{b}\end{array}$ & $\begin{array}{c}\text { p-value } \\
60 / \text { open }^{b)}\end{array}$ \\
\hline MRI-AQ & $20.5(18-23.25)$ & $20.5(18-26.25)$ & 0.433 & $29(26-34)$ & $<0.001$ & $<0.001$ \\
\hline $\begin{array}{l}\text { MRI-AQ } \\
\text { Anxiety }\end{array}$ & $16(15-17.25)$ & $16(15-20.5)$ & 0.215 & $23(20-27.5)$ & $<0.001$ & $<0.001$ \\
\hline $\begin{array}{l}\text { MRI-AQ } \\
\text { Relaxation }\end{array}$ & $4(3-6)$ & $4(3-6)$ & 0.805 & $6(6-9)$ & $<0.001$ & $<0.001$ \\
\hline $\begin{array}{l}\text { Patient } \\
\text { Worry* }\end{array}$ & $1(1-2)$ & $1(1-2.25)$ & 0.470 & $4(2-6)$ & $<0.001$ & $<0.001$ \\
\hline $\begin{array}{l}\text { Patient } \\
\text { Experience* }\end{array}$ & $1(1-2)$ & $1(1-2.25)$ & 0.163 & $2(1-5)$ & $<0.001$ & 0.018 \\
\hline STAI-S & $27(23-33.75)$ & $28(23-39)$ & 0.914 & $35(27-43.5)$ & 0.003 & 0.003 \\
\hline
\end{tabular}

MRI-AQ= Magnetic Resonance Imaging-Anxiety Questionnaire, STAI-S = Spielberg State and Trait Index-State. *Single items patients rated their worry and experience on a ten-point scale. ${ }^{a)}=$ Median (interquartile range) $\left.{ }^{b}\right)=$ Mann Whitney U-test, $\mathrm{n}=$ number of participants, $\mathrm{n}=$ number of participants $\mathrm{n}=$ number of participants. Significant values in bold.

The staff evaluation on single items of patient "worry" and "experience" showed significant differences between all groups. Patients in the $70 \mathrm{~cm}$ bore reported the lowest level of worry, whereas high worry was experienced in relation to the open scanner (Table 4). When patient and staff ratings on the single items experience/worry were compared, the greatest differences were seen in patient "worry" in the open scanner, where the patients rated their "worry" worse than the staff did.

Table 4. Staff ratings on single items of patient experience and worry for the three scanners

\begin{tabular}{lllllcc}
\hline & $\begin{array}{l}70 \mathrm{~cm}^{\text {a) }} \\
(\mathrm{n}=55)\end{array}$ & $\begin{array}{l}60 \mathrm{~cm}^{\text {a) }} \\
(\mathrm{n}=51)\end{array}$ & $\begin{array}{l}\mathrm{p} \text {-value } \\
70 / 60^{\text {b) }}\end{array}$ & $\begin{array}{l}\text { open }^{\text {a) }} \\
(\mathrm{n}=49)\end{array}$ & $\begin{array}{c}\mathrm{p} \text {-value } \\
70 / \text { open }^{\text {b) }}\end{array}$ & $\begin{array}{c}\mathrm{p} \text {-value } \\
60 / \text { open }^{\text {b) }}\end{array}$ \\
\hline Worry & $1(1-1)$ & $2(1-3)$ & $<\mathbf{0 , 0 0 1}$ & $3(1-6)$ & $<0,001$ & $\mathbf{0 . 0 0 6}$ \\
Experience & $1(1-1)$ & $2(1-3)$ & $<0,001$ & $2(1-3)$ & $<0,001$ & 0,396 \\
\hline \hline
\end{tabular}

${ }^{a)}=$ Median (interquartile range), ${ }^{b}=$ Mann Whitney test, $n=$ number of participants 


\section{One week after the examination}

After one week, the patients examined in the $70 \mathrm{~cm}$ bore rated their experience of the examination significantly $(\mathrm{p}<0.001)$ better than patients in the $60 \mathrm{~cm}$ bore. Patients examined in the open scanner experienced significantly higher levels of anxiety measured with all scales (Table 5).

Table 5. Questionnaires answered one week after the examination

\begin{tabular}{lcccccc}
\hline & $\begin{array}{c}70 \mathrm{~cm} \\
\left.(\mathrm{n}=42)^{\mathrm{a}}\right)\end{array}$ & $\begin{array}{c}60 \mathrm{~cm} \\
\left.(\mathrm{n}=39)^{\mathrm{a}}\right)\end{array}$ & $\begin{array}{c}\mathrm{p} \text {-value } \\
70 / 60 \mathrm{~b})\end{array}$ & Open $(\mathrm{n}=28)^{\mathrm{a})}$ & $\begin{array}{c}\mathrm{p} \text {-value } \\
70 / \text { open }^{\mathrm{b})}\end{array}$ & $\begin{array}{c}\mathrm{p} \text {-value } \\
60 / \text { open }\end{array}$ \\
\hline MRI-AQ & $18.5(16-23)$ & $19(16-26)$ & 0.578 & $30(24-38)$ & $<\mathbf{0 . 0 0 1}$ & $<\mathbf{0 . 0 0 1}$ \\
$\begin{array}{l}\text { MRI-AQ } \\
\text { Anxiety }\end{array}$ & $14(12-16)$ & $14(13-19)$ & 0.292 & $23.5(18.25-30.75)$ & $<\mathbf{0 . 0 0 1}$ & $<\mathbf{0 . 0 0 1}$ \\
$\begin{array}{l}\text { MRI-AQ } \\
\text { Relaxation }\end{array}$ & $5(3-6)$ & $6(3-7)$ & 0.796 & $7(6-9.5)$ & $\mathbf{0 . 0 0 1}$ & $<\mathbf{0 . 0 0 1}$ \\
$\begin{array}{l}\text { Patient } \\
\text { Worry* }\end{array}$ & $1(1-2)$ & $1(1-3)$ & 0.097 & $4(3-6)$ & $<\mathbf{0 . 0 0 1}$ & $<\mathbf{0 . 0 0 1}$ \\
$\begin{array}{l}\text { Patient } \\
\text { Experience* }\end{array}$ & $1(1-2)$ & $2(1-3)$ & $\mathbf{0 . 0 2 5}$ & $4(2-6)$ & $<\mathbf{0 . 0 0 1}$ & $\mathbf{0 . 0 0 8}$ \\
$\begin{array}{l}\text { HAD A } \\
\text { HAD D }\end{array}$ & $4(1-6)$ & $1(0-7)$ & 0.208 & $7(4-9.75)$ & $\mathbf{0 . 0 0 3}$ & $\mathbf{0 . 0 0 1}$ \\
MRI-FSS & $14(10-4.25)$ & $1(0-4)$ & 0.268 & $3(1-5.75)$ & 0.215 & $\mathbf{0 . 0 2 8}$ \\
\hline \hline
\end{tabular}

MRI-AQ= Magnetic Resonance Imaging-Anxiety Questionnaire, HAD A = Hospital Anxiety and Depression scale Anxiety, Had D = Hospital Anxiety and Depression scale Depression, MRI-FSS Magnetic Resonance Imaging-fear survey Schedule.

*Single items patients rated their worry and experience on a ten-point scale. ${ }^{\mathrm{a}}{ }^{\mathrm{a}}=$ Median (interquartile range), $\left.{ }^{\mathrm{b}}\right)=\mathrm{Mann}$ Whitney U-test, $n=$ number of participants

\section{Comparisons before the examination, directly after and one week later}

Only patients who answered the questionnaires twice were included (Fig 1). Patient anxiety during MRI (MRI-AQ) was reported on a lower level at one week after the examination, compared with directly after, for those examined in the $60 \mathrm{~cm}$ or the $70 \mathrm{~cm}$ scanner.

Regarding Single items, (worry/experience) patients rated their worry and experience on a ten-point scale. For the factor "relaxation", no temporal difference was found in the $60 \mathrm{~cm}$ group, while the patients in the $70 \mathrm{~cm}$ scanner judged "relaxation" during examination as worse after one week. The group examined in the open scanner, rated "anxiety" and "relaxation" without change after one week. The patient ratings of "experience" and "worry" showed no difference over time for the $70 \mathrm{~cm}$ scanner. Patients examined in the $60 \mathrm{~cm}$ bore 
scanner rated both "experience" and "worry" as worse one week after the examination. The group in the open scanner judged their "experience" after one week as worse compared to immediately after, while no differences were found for worry (Table 6).

Table 6. Comparison between patient ratings of MRI-AQ, experience and worry directly and one week after the examination. Only patients answering the questionnaires both directly after and one week after the examination were included.

\begin{tabular}{|c|c|c|c|c|c|c|c|c|c|}
\hline & \multicolumn{3}{|c|}{70 cm scanner $(n=42)$} & \multicolumn{3}{|c|}{$60 \mathrm{~cm}$ scanner $(n=39)$} & \multicolumn{3}{|c|}{ Open scanner $(n=28)$} \\
\hline & $\begin{array}{c}\text { Directly } \\
\text { after }^{\text {a) }}\end{array}$ & $\begin{array}{c}\text { One week } \\
\text { after }{ }^{\text {a) }}\end{array}$ & $\begin{array}{c}\text { p- } \\
\text { value }^{\text {b) }}\end{array}$ & $\begin{array}{l}\text { Directly } \\
\text { after }^{\text {a) }}\end{array}$ & $\begin{array}{l}\text { One week } \\
\text { after a) }\end{array}$ & $\begin{array}{c}\text { P- } \\
\text { Value }\end{array}$ & $\begin{array}{l}\text { Directly } \\
\text { after }^{\text {a) }}\end{array}$ & $\begin{array}{c}\text { One Week } \\
\text { after }^{\text {a) }}\end{array}$ & $\begin{array}{c}\text { p- } \\
\text { value }^{b)}\end{array}$ \\
\hline $\begin{array}{l}\text { MRI-AQ } \\
\text { Total }\end{array}$ & $20(18-22)$ & $18(16-22)$ & 0.005 & $21(18-26)$ & $19(16-26)$ & 0.013 & $31(26-36)$ & $28(24-37)$ & 0.231 \\
\hline $\begin{array}{l}\text { MRI-AQ } \\
\text { Anxiety }\end{array}$ & $16(15-17)$ & $14(12-15.25)$ & $>0.001$ & $16(15-20)$ & $15(12-19)$ & 0.005 & $24(20-29)$ & $21.5(18-29.75)$ & 0.111 \\
\hline $\begin{array}{l}\text { MRI-AQ } \\
\text { Relaxation }\end{array}$ & $4(3-6)$ & $5(3-6)$ & 0.033 & $4(3-6)$ & $4(3-6)$ & 0.350 & $6.5(5.25-9)$ & $7(6-9)$ & 0.598 \\
\hline Experience* & $1(1-2)$ & $1(1-2)$ & 0.510 & $2(1-2)$ & $2(1-3)$ & 0.048 & $3(1-5)$ & $4(2-6)$ & 0.009 \\
\hline Worry* & $1(1-2)$ & $1(1-2)$ & 0.221 & $1(1-2)$ & $1(1-3)$ & 0.017 & $4(2-6.75)$ & $4(3-6)$ & 0.580 \\
\hline
\end{tabular}

MRI-AQ- Magnetic Resonance Imaging-Anxiety Questionnaire, Total-the total instrument MRI-AQ, anxiety- the factor anxiety, relaxation - the factor relaxation *Single items patients rated their worry and experience on a ten-point scale. ${ }^{a}=$ Median (interquartile range), ${ }^{b}$ Wilcoxon signed-rank test. $n=$ number of participants

Anxiety (STAI-S) decreased $(\mathrm{p}<0.001)$ in all three groups directly after the examination compared to before. When compared before and one week after the examination, no differences were found regarding anxiety (HAD-A), depression (HAD-D, ) and fear of situations related to MRI examinations (MRI-FSS).

\section{Males and females}

In the following aspects, women showed significantly higher anxiety level compared to men on the day of the examination: Experience $(p=0.022)$, worry $(p=0.004$, MRI-FSS $(p>0.001)$, MRI-AQ - total questionnaire ( $\mathrm{p}>0.001)$, MRI-AQ Anxiety $(\mathrm{p}=0.001)$ and MRI_AQ Relaxation $(\mathrm{p}>0.001)$. One week after the examination, women still showed higher anxiety level than men: Experience $(p=0.021)$, worry $(p=0.014)$, MRI-FSS $(p=0.001)$, MRI-AQ questionnaire ( $\mathrm{p}=0.002)$ and MRI-AQ Relaxation $(\mathrm{p}=0.02)$. 


\section{Discussion}

Several previously published studies investigate the effect of the tunnel diameter on image quality. However, there is little recent quantitative empirical research related to patient anxiety and experience in clinical practice in different scanners. This study aimed to illustrate patient anxiety in two scanners with bore diameters of $60 \mathrm{~cm}$ and $70 \mathrm{~cm}$, and also as a secondary aim the patient condition in an open scanner. This research provides valuable information for professionals interested in improving the wellbeing of their patients.

All patients experienced less state anxiety (STAI-S) after the examination than before the procedure, probably as a sign of relief after the completed investigation. As single items, “experience" and "worry" showed no difference immediately after compared to one week after the examination for the $70 \mathrm{~cm}$ group. The group examined in the $60 \mathrm{~cm}$ bore tended to rate their "experience" and "worry" worse after one week. Patients in the open scanner judged their "experience" as worse, but their "worry" was unchanged after one week. It is likely that some of the patients examined in the $60 \mathrm{~cm}$ bore but especially in the open scanner will experience severe anxiety if they need to have the investigation repeated. In order to avoid future complications, it is important to debrief the patient about the anxietyprovoking situation.

In a group-based comparison, patients in the $70 \mathrm{~cm}$ scanner recalled their "experience" of the examination more positively than did those in the $60 \mathrm{~cm}$ bore. The staff, who were all experienced radiographers working with MRI, also rated patient "experience" and "worry" higher (worse) for the patients in the $60 \mathrm{~cm}$ scanner than in the $70 \mathrm{~cm}$ scanner. It should be born in mind, though, that the score provided by the patient is the "gold standard". 
Even if no differences were seen on the day of the examination, recall of the examination was more positive for the group in the $70 \mathrm{~cm}$ bore. Altogether, this indicates that the $70 \mathrm{~cm}$ bore is preferable for patients.

In this study we show that patients examined in the open scanner in a clinical setting, expressed high levels of pre-test anxiety which may have motivated them to ask for referral to an open design scanner. This high anxiety rating was evident also in the follow-up. Even if workers within the MR community are aware of the plight of some patients it is important to increase the awareness of referring physicians regarding patient investigative anxiety. Although examined in an open scanner they had high levels of anxiety and scored worse for generic (STAI-S, HAD-A) and specific anxiety (MRI-AQ with the factors anxiety and relaxation) and fear (MRI-FSS) before, directly after and one week after the examination as well as for the two single items about "experience" and "worry", compared to the groups in the closed bores. The staff also scored the patients "experience" and "worry" in the open scanner group as poorer than in the other two scanners. As Lang et al. we found that the most anxious patients are examined in open scanners ${ }^{29}$. In some previous studies, patients have displayed a higher tolerance of being scanned in an open scanner, compared to closed bores ${ }^{15,30}$. Nearly all patients in this study had requested to be examined there due to difficulties while being examined in a tunnel-like bore, even if claustrophobia per se was not an inclusion criterion. Referral to an open scanner could be the only way for those patients to endure a complete examination. The patients in the closed bores were recruited from a waiting list without having expressed particular wishes regarding the type of scanner.

In a previous study, when reminded one month after being examined, about $30 \%$ of the respondents experienced increased feelings of anxiety, and about one third were unwilling or hesitant to undergo a new MRI scan ${ }^{31}$. On the contrary, in our study, levels of anxiety decreased over time in the closed bore, but the open scanner patients maintained the same 
level of anxiety one week after the examination (MRI-AQ) as immediately after the scan. Reduced anxiety over time may allow patients to undergo a new examination, if required. On the contrary, patients examined in the open scanner seem to constitute a separate group with different and extensive problems that do not resolve over time.

Compared to previous studies ${ }^{15,30}$, the scores in the STAI-S and MRI-FSS were lower (indicating less anxiety) in the present study. In the previous studies, inclusion criteria were claustrophobia, whereas in the present study the participants were consecutive patients in clinical settings, but some had explicitly asked to be examined in the open scanner. Studies comparing the number of claustrophobic events, regardless of whether the patients were screened for claustrophobia or not, have shown that wider, shorter and open scanners are always preferred by patients, compared to more narrow scanners ${ }^{15,30,32,33}$. For patients with scanning anxiety the advantage of an open scanner seems to be considerable, but at a cost mainly related to decreased image quality ${ }^{34}$. In comparisons between open scanners and those with a closed bore, image quality is superior in scanners with a closed bore ${ }^{35}$. However, in retrospective evaluations, image quality has been found to be acceptable in open design scanners ${ }^{36}$. It is more important that the patient completes an examination with somewhat lower image quality than having an aborted study in a closed-bore scanner. The clinical MRI market is dominated by closed bores at $1.5 \mathrm{~T}$ followed by $3 \mathrm{~T}^{37,38}$.

Our study confirms findings from other studies ${ }^{14,39}$ where women express higher levels of anxiety than men.

For anxious patients, examinations in an open scanner or some kind of supporting interventions before or during the examination can be tried ${ }^{21,28,29}$. Even if tunnel-like scanners are produced with a wider and shorter bore, such efforts may be limited by the appearance of additional problems also in patients without anxiety in relation to MRI. Better 
scan information, in the form of a video clip or an informative telephone call have shown promising results $21,40,41$. This is an easy way to make patients feel more relaxed. If patients can watch the video at home, their preparation becomes time-effective. Watching the video could also be a way to process an unpleasant experience. Extended written information has produced reduced motion artefacts in images ${ }^{14}$. In practice, it is the responsibility of the radiographer to take the time to prepare the patient especially since studies have shown tailored information to have a positive effect reducing motion artefacts ${ }^{14,42}$.

The interaction between the patient and the staff should be highlighted, regardless whether the scanner is open or has a wide bore ${ }^{19,43,44}$.

\section{Limitations}

In this study, consecutive patients were referred for MRI of the spine in one of three different MRI scanners. A randomized procedure or a procedure where the patient is their own control would have been preferable. However, the extent of cooperation and the time required to perform 3 different MRI investigations precluded such a strategy.

The study used valid and reliable instruments. To assess experience, worry and other sensation and emotions, ten-point scales have been widely used.

Body mass index (BMI) and prior patient MRI experiences, factors known to influence scanning anxiety, were not studied which may affect the generalizability of the study results. In a randomized controlled trial on claustrophobia in MRI, patients with prior negative experiences from MRI did not show significantly higher BMI or higher pre-imaging anxiety (STAI) than patients without those experiences ${ }^{15}$.

The patients who rated the highest levels of anxiety immediately after the scan showed clearly lower participation rate at the second administration of the patient questionnaire. If they had participated in the delayed questionnaire, the result could have been different. The 
response rate at the follow up, one week after examination was completed by $80 \%$ of the study participants for the closed bore and $57 \%$ for the open scanner

Patients examined in the open scanner were used as a backdrop to our closed bore study groups: they expressed significantly higher anxiety and had to a large extent expressed a preference to have an open bore scan. Furthermore, patients in the open scanner showed a completely different profile with high level ratings of anxiety and low ratings of relaxation which did not change over time. Their only way to cope with a scan was to be examined in the open scanner.

\section{Conclusion}

When patient experience of the MRI examination in the $60 \mathrm{~cm}$ and $70 \mathrm{~cm}$ bores was compared it was similar immediately after the examination. However, patient recall of the examination was more pleasant for those examined in the $70 \mathrm{~cm}$ bore scanner. Additionally, the staff evaluation indicated that the $70 \mathrm{~cm}$ bore scanner was more favorable for the patients than the $60 \mathrm{~cm}$ scanner.

It has been illustrated that MRI in an open scanner may be the only way for patients with anxiety problems to endure an examination. If open scanners are unavailable, different interventions are needed to enable these patients to undergo an examination. Patient anxiety in connection with MRI is a challenge for the radiographers necessitating constant improvements in coaching as well as in investigative technology. 


\section{References}

1. Eurostat Statistic explained ES: Health in the European Union - facts and figures In. Edited by Eurostat, 15 nov 2018 edn. [accesed 31 january 2019],

https://ec.europa.eu/eurostat/statistics_explained/index.php?title=Health_in_the_European_U nion_\%E2\%80\%93_facts_and_figures 2018 .

2. OECD: Magnetic resonance imaging (MRI) exams (indicator).In OECD Health

Statistics: OECD; 2018. [accesed 31 january, 2019]

https://data.oecd.org/healthcare/magnetic-resonance-imaging-mri exams.htm doi: $10.1787 / 1 \mathrm{~d} 89353 \mathrm{f}$-en

.3. C. Silverstine,Europe's Looming Radiology Capacity Challenge a Compartive Study, United Kingdom,France, Germany,Sweden \& Denmark, Healthmanagement.org, Volume 16, Issue 1, 2016, [accesed 31 january, 2019], https://www.telemedicineclinic.com/wp_content/uploads/2016/11/Europes_looming_radiolo gy_capacity_challenge-A_comparitive_study.pdf

4. Schenck JF: Safety of strong, static magnetic fields. J Cardiovasc Magn Reson 2000, 12(1):2-19. doi.org/10.1002/1522-2586(200007)12:1<2::AID-JMRI2>3.0.CO;2-V

5. Tischler V, Calton T, Williams M, Cheetham A: Patient anxiety in magnetic resonance imaging centres: Is further intervention needed? Radiography 2008, 14(3):265-266. doi.org/10.1016/j.radi.2007.09.0076. Tornqvist E, Mansson A, Larsson EM, Hallstrom I. It's like being in another world--patients' lived experience of magnetic resonance imaging. Journal of clinical nursing 2006; 15:954-961.

7. Katznelson R, Djaiani GN, Minkovich L, Fedorko L, Carroll J, Borger MA, Cusimano RJ, Karski J: Prevalence of claustrophobia and magnetic resonance imaging after coronary artery bypass graft surgery. Neuropsychiatric Disease and Treatment 2008, 4(2):487-493. doi.org/10.2147/NDT.S2699.

8. Murphy KJ, Brunberg JA: Adult claustrophobia, anxiety and sedation in MRI. Magnetic Resonance Imaging 1997, 15(1):51-54. doi.org/10.1016/S0730-725X(96)00351-7

9. Harris LM, Cumming SR, Menzies RG: Predicting anxiety in magnetic resonance imaging scans. International Journal of Behavioral Medicine 2004, 11(1):1-7. doi.org10.1207/s15327558ijbm1101_1

10. Brand J, Kopke S, Kasper J, Rahn A, Backhus I, Poettgen J, Stellmann JP, Siemonsen S, Heesen C: Magnetic resonance imaging in multiple sclerosis--patients' experiences, information interests and responses to an education programme. PloS one 2014, 9(11):e113252. doi.org/10.1371/journal.pone.0113252

11. Katz RC, Wilson L, Frazer N: Anxiety and its determinants in patients undergoing magnetic resonance imaging. Journal of behavior therapy and experimental psychiatry 1994 , 25(2):131-134. doi.org/10.1016/0005-7916(94)90005-1

12. Eshed I, Althoff CE, Hamm B, Hermann KG: Claustrophobia and premature termination of magnetic resonance imaging examinations. Journal of magnetic resonance imaging : JMRI 2007, 26(2):401-404. doi.org/10.1002/jmri.21012.

13. Bangard C, Paszek J, Berg F, Eyl G, Kessler J, Lackner K, Gossmann A: MR imaging of claustrophobic patients in an open $1.0 \mathrm{~T}$ scanner: motion artifacts and patient acceptability compared with closed bore magnets. European journal of radiology 2007, 64(1):152-157. doi.org/10.1016/j.ejrad.2007.02.012. 
14. Tornqvist E, Mansson A, Larsson EM, Hallstrom I: Impact of extended written information on patient anxiety and image motion artifacts during magnetic resonance imaging. Acta Radiol 2006, 47(5):474-480. doi.org/10.1080/02841850600690355

15. Enders J, Zimmermann E, Rief M, Martus P, Klingebiel R, Asbach P, Klessen C, Diederichs G, Wagner M, Teichgräber U, Bengner T, Hamm B, Dewey M: Reduction of claustrophobia with short-bore versus open magnetic resonance imaging: a randomized controlled trial. PloS one 2011; 6:e23494. https://doi.org/10.1371/journal.pone.0023494

16. Munn Z, Jordan Z: Interventions to reduce anxiety, distress and the need for sedation in adult patients undergoing magnetic resonance imaging: a systematic review. International journal of evidence-based healthcare 2013, 11(4):265-274. doi:10.1111/1744-1609.12045

17. Caruso A, Bongiorno L, Vallini I, Russo P, Tomao F, Grandinetti M: Breast cancer and distress resulting from magnetic resonance imaging (MRI): the impact of a psychological intervention of emotional and informative support. J Exp Clin Cancer Res 2006, 25(4):499..

18. Thorpe S, Salkovskis PM, Dittner A: Claustrophobia in MRI: the role of cognitions. Magnetic Resonance Imaging 2008, 26(8):1081-1088. doi.org/10.1016/j.mri.2008.01.022

19. Youssefzadeh S, Eibenberger K, Helbich T, Dorffner R, Dantendorfer K, Breitenseher M, Wolf G: Reduction of adverse events in MRI of the breast by personal patient care. Clinical radiology 1997, 52(11):862-864. doi.org/10.1016/S0009-9260(97)80082-7

20. work of the current authors

21. work of the current authors

22. Spielberger CD, Goursch, R.L., Lushene, R.E. Manual for the State-Trait Anxiety Inventory. Palo Alto, CA: Consulting Psychologist Press 1970.

23. Zigmond AS, Snaith RP: The hospital anxiety and depression scale. Acta Psychiatr Scand 1983, 67(6):361-370. doi.org/10.1111/j.1600-0447.1983.tb09716.x

24. Wolpe J, Lang PJ: A Fear Survey Schedule For Use In Behaviour Therapy. Behaviour Research and Therapy 1964, 2:27-30.

25. Lukins R, Davan IGP, Drummond PD: A cognitive behavioural approach to preventing anxiety during magnetic resonance imaging. Journal of behavior therapy and experimental psychiatry 1997, 28(2):97-104. doi.org/10.1016/S0005-7916(97)00006-2

26. Association WM: World Medical Association Declaration of Helsinki. Ethical principles for medical research involving human subjects. Bulletin of the World Health Organization 2001, 79(4):373.

27. ICH Harmonised Tripartite Guidline For Good Clinical Practice, Postgrad Med J 2001, 47(1):45-50.

28. Selim MA. Effect of pre-instruction on anxiety levels of patients undergoing magnetic resonance imaging examination. Eastern Mediterranean health journal $=\mathrm{La}$ revue de sante de la Mediterranee orientale $=$ al-Majallah al-sihhiyah li-sharq al-mutawassit 2001; 7:519-525.

29. Lang EV, Ward C, Laser E: Effect of team training on patients' ability to complete MRI examinations. Academic radiology 2010, 17(1):18-23. doi.org/10.1016/j.acra.2009.07.002

30. Bangard C, Paszek J, Berg F, Eyl G, Kessler J, Lackner K, Gossmann A: MR imaging of claustrophobic patients in an open 1.0T scanner: motion artifacts and patient acceptability compared with closed bore magnets. European journal of radiology 2007, 64(1):152-157. doi.org/10.1016/j.ejrad.2007.02.012 
31. McIsaac HK, Thordarson DS, Shafran R, Rachman S, Poole G: Claustrophobia and the magnetic resonance imaging procedure. J Behav Med 1998, 21(3):255-268.

32. Dewey M, Schink T, Dewey CF: Claustrophobia during magnetic resonance imaging: cohort study in over 55,000 patients. Journal of magnetic resonance imaging: JMRI 2007, 26(5):1322-1327. doi.org/10.1002/jmri.21147

33. Hunt CH, Wood CP, Lane JI, Bolster BD, Bernstein MA, Witte RJ: Wide, short bore magnetic resonance at 1.5 t: reducing the failure rate in claustrophobic patients. Clin Neuroradiol 2011, 21(3):141-144. doi.org/141-144. 10.1007/s00062-011-0075-4

34. Zhao J, Krug R, Xu D, Lu Y, Link TM: MRI of the spine: image quality and normalneoplastic bone marrow contrast at $3 \mathrm{~T}$ versus 1.5 T. AJR Am J Roentgenol 2009, 192(4):873-880.

35. Enders J, Rief M, Zimmermann E, Asbach P, Diederichs G, Wetz C, Siebert E, Wagner M, Hamm B, Dewey M: High-field open versus short-bore magnetic resonance imaging of the spine: a randomized controlled comparison of image quality. PloS one 2013, 8(12):e83427. doi.org/10.1371/journal.pone. 0083427

36. Lu JC, Nielsen JC, Morowitz L, Musani M, Ghadimi Mahani M, Agarwal PP, Ibrahim el SH, Dorfman AL: Use of a 1.0 Tesla open scanner for evaluation of pediatric and congenital heart disease: a retrospective cohort study. J Cardiovasc Magn Reson 2015, 17:39. doi.org/10.1186/s12968-015-0144-y

37. Bangerter NK, Taylor MD, Tarbox GJ, Palmer AJ, Park DJ: Quantitative techniques for musculoskeletal MRI at 7 Tesla. Quantitative imaging in medicine and surgery 2016, 6(6):715-730. doi.org/10.21037/qims.2016.12.12

38. Inglese M, Fleysher L, Oesingmann N, Petracca M: Clinical applications of ultra-high field magnetic resonance imaging in multiple sclerosis. Expert review of neurotherapeutics 2018. doi.org/10.1080/14737175.2018.1433033

39. Luck A, Pearson S, Maddern G, Hewett P: Effects of video information on precolonoscopy anxiety and knowledge: a randomised trial. Lancet (London, England) 1999, 354(9195):2032-2035. doi.org/10.1016/S0140-6736(98)10495-6

40. Tugwell JR, Goulden N, Mullins P: Alleviating anxiety in patients prior to MRI: A pilot single-centre single-blinded randomised controlled trial to compare video demonstration or telephone conversation with a radiographer versus routine intervention. Radiography (London, England : 1995) 2018; 24:122-129. doi: 10.1016/j.radi.2017.10.001. Epub 2017 Oct 31 .

41. Tugwell-Allsup J, Pritchard AW: The experience of patients participating in a small randomised control trial that explored two different interventions to reduce anxiety prior to an MRI scan. Radiography (London, England : 1995) 2018; 24:130-136. doi: 10.1016/j.radi.2017.11.001. Epub 2017 Dec 11.

42. Tazegul G, Etcioglu E, Yildiz F, Yildiz R, Tuney D: Can MRI related patient anxiety be prevented? Magn Reson Imaging 2015, 33(1):180-183. doi.org/10.1016/j.mri.2014.08.024

43. Carlsson S, Carlsson E: 'The situation and the uncertainty about the coming result scared me but interaction with the radiographers helped me through': a qualitative study on patients' experiences of magnetic resonance imaging examinations. Journal of clinical nursing 2013, 22(21-22):3225-3234. doi.org/10.1111/jocn. 12416

44. Strand T, Tornqvist E, Rask M, Roxberg A: Caring for patients with spinal metastasis during an MRI examination. Radiography (London, England : 1995) 2018; 24:79-83. doi:

10.1016/j.radi.2017.06.001. Epub 2017 Jun 20. 